\title{
Financial Development and Inequality: Brazil 1985-99
}

\author{
Manoel F. Meyer Bittencourt
}

Discussion Paper No. 06/582

January 2006

Department of Economics

University of Bristol

8 Woodland Road

Bristol BS8 1TN 


\title{
Financial Development and Inequality: Brazil 1985-99*
}

\author{
Manoel F. Meyer Bittencourt ${ }^{\dagger}$ \\ University of Bristol, Department of Economics
}

January 29, 2006

\begin{abstract}
We examine the impact that financial development had on earnings inequality in Brazil in the 1980's and 90's. The empirical evidence, based on panel time series and time series data, shows that more broad access to financial and credit markets had a significant and robust effect in reducing inequality during the period investigated. We suggest that this is not only because the poor can invest the acquired credit in all sorts of productive activities, but also because those with access to financial markets can insulate themselves against recurrent poor macroeconomic performance, which is exemplified by high inflation rates. The main implication of the results is that a seemingly nondistortionary policy, such as more credit aimed at the poor, alleviates the extreme inequality present in Brazil and consequently improves welfare without distorting economic efficiency.

Keywords: Financial development and markets, credit, inequality and welfare, inflation.
\end{abstract}

JEL Classification: D31, E44, O11, O54.

${ }^{*}$ I thank Paul Gregg, Edmund Cannon, Andrew Pickering, Sonia Bhalotra, Melanie Khamis, Yuji Tamura, Fabien Postel-Vinay, Jon Temple and seminar participants at Bristol for fruitful conversations and comments. I also thank Ron Smith and Frank Windmeijer for the clarifying correspondence about some empirical issues of this paper. Financial support from the Economics Department at Bristol is gratefully acknowledged. Remaining errors are my own responsibility.

${ }^{\dagger}$ E-mail for correspondence: mb9591@bristol.ac.uk. 


\section{Introduction}

\subsection{Motivation and Overview}

Brazil is a major developing country that has been known for its high earningsincome inequality and also for presenting poor macroeconomic performance, particularly in the 1980's and first half of the 90's. The high inequality is exemplified by a Gini coefficient of .63 in 1989 and the poor macroeconomic performance by very high and volatile inflation rates $^{1}$.

The importance of financial development in such an economic environment is twofold: firstly, more access to credit markets benefits the poor via the investment in productive activities channel. With more access to credit the poor can invest in, e.g., their own education and that of their offspring. They can then increase and improve their mobility and economic prospects, and hence break the cycle of persistent inequality. Secondly, in countries which presented not only high and volatile inflation rates for such a long time but also periods of hyperinflation, access to financial markets and other fully indexed assets offer to those at the top of the distribution even daily indexed protection of their earnings-income against high inflation. However, the poor, who are financial markets constrained, have to hold cash instead, and in a high inflation environment those holding cash lose much more with high inflation via the inflation-tax channel. Hence, financial development in Brazil, and most certainly in other developing countries too, is important because it provides the poor with the much needed credit to be invested in all sorts of productive activities and because it offers to those with access to financial markets protection against chronic poor macroeconomic performance $^{2}$.

Having said that, we use data covering the period between 1985-99 to examine the impact that the financial and credit markets had on earnings inequality in regional Brazil. The time span of the data is particularly interesting because it covers two very distinct periods of the Brazilian economy. First, the high inflation period (1985-94) with rates of up to eighty two percent

\footnotetext{
${ }^{1}$ Other developing countries that presented similar poor economic conditions, with high inequality and high inflation rates were, e.g., Bolivia, Colombia, Indonesia, Mexico, Peru and Tanzania.

${ }^{2}$ As bluntly put by the Inter-American Development Bank recently: "An interruption in credit supply can lead to a disruption in investment and economic growth and prosperity", Inter-American Development Bank (2005).
} 
per month, and then a period with more stable macroeconomic conditions (1995-99) when inflation was on average at nine percent for the period ${ }^{3}$.

The empirical evidence presented clearly shows that financial development had a significant effect in reducing inequality at the time. Furthermore, the results are robust for different measures of financial development and inequality, different specifications and estimators, and different time periods. The main policy implication emerging from these results is that more access to financial markets and credit, especially by the poor, has the advantage of being a non-distortionary (e.g., fiscal) policy that alleviates inequality, and therefore improves the welfare of those at the bottom of the earnings distribution without negatively affecting economic efficiency.

What distinguishes this paper from the previous empirical studies is that firstly, as suggested by Besley and Burgess (2003), we carry out a much needed national and subnational study on the subject. This can be regarded as a step forward from the previous international cross-sectional $N \rightarrow \infty$ and panel $N \succ T$ studies for the reliability of the national and subnational data in better pinpointing the effects of financial development on inequality at a more disaggregated level. Secondly, we use not only the available time series $T \rightarrow \infty$ variation in the data but also construct and explore the variation of a panel time series $T \succ N$ data set. Thirdly, we use the usual measures of financial development, but also extra measures that we believe capture more appropriately and realistically the Brazilian economic reality. Fourthly, we take into consideration the importance of having access to financial markets for the additional insulation provided in times of poor macroeconomic performance.

The remainder of this paper has the following structure: the next subsection reviews the previous theoretical and empirical literature. Section Two describes the data set, presents the descriptive statistics and correlations amongst the main variables, and shows how financial development and inequality behaved over the period. Section Three explains the strategy used to deal with some empirical issues and presents the main results obtained. Finally, Section Four concludes the paper; it summarises the main findings, discusses the significance of the results and also their limitations, and examines the policy implications and advantages of having more access to financial and credit markets.

\footnotetext{
${ }^{3}$ It is worth mentioning tough, that the annual inflation rate in 1995 was still at $21.98 \%$ and at $9.11 \%$ in 1996.
} 


\subsection{Related Literature}

Loury (1981), Galor and Zeira (1993) and Banerjee and Newman (1993), all in their own ways, work on the basic theoretical assumption that the poor lack initial wealth and therefore need more broad access to credit, which can be invested in the formation of human capital or any other sort of productive activity. However, because of moral hazard, financial and credit markets are imperfectly accessed by those at the bottom of the earnings-income distribution. The main common prediction of these theoretical models is that these imperfections determine the occupational outcomes of an economy, with the poor becoming wage earners and the rich becoming entrepreneurs. This social immobility of the poor consequently widens the distribution of earningsincome. On a slightly different strand, Greenwood and Jovanovic (1990) develop a model that predicts a Kuznets curve (Kuznets (1955)), i.e., an economy in its initial stages of financial development would present increasing inequality and only in a second or even third stage of development would inequality actually decrease. Furthermore, Aghion and Bolton (1997) argue that more access to credit is not a sufficient condition to reduce inequality for the trickle-down mechanism occurs only at very high rates of capital accumulation. Because of that, they advocate (as Loury (1981) and Banerjee and Newman (1993) had done before) some redistribution, which would improve efficiency and welfare in the early stages of development. Finally, Piketty (1997) argues that imperfect credit markets lead to high interest rates and low credit market intermediation. With that imperfect access to credit the economic mobility of the poor is reduced when compared to the rich, and inequality increases ${ }^{4}$.

In relation to the fact that the poor do not have access to financial markets and consequently no access to the insulation provided in times of high inflation rates by, e.g., simple but monthly or even daily indexed bank accounts, Lucas and Stokey (1987) and Cooley and Hansen (1989), develop theoretical models that can be in some ways linked to this question. In an economy with cash-in-advance constraints, high inflation and indeed hyperinflation act as a tax on cash (non-indexed) goods, therefore leading people to reallocate or substitute their cash for credit (indexed) goods. However, in Brazil and other developing countries, the poor are credit-goods (financial and credit markets) constrained, having to hold cash instead, and hence los-

\footnotetext{
${ }^{4}$ For a more thorough review of some of these theoretical studies, see Aghion, Caroli, et al. (1999) or Aghion and Bolton (1992).
} 
ing or being taxed much more with high inflation than those at the top of the distribution. With that, inequality naturally widens ${ }^{5}$.

Bulir (1998), Honohan (2004) and Beck, Demirguc-Kunt, et al. (2004), use cross-sections of countries, each with different empirical strategies, and all find that financial development alleviates either inequality or poverty. Li, Squire, et al. (1998), Dollar and Kraay (2002) and Clark, Xu, et al. (2003), use panels of countries instead, and their results confirm the prediction that more access to financial and credit markets help either to reduce inequality or to improve the incomes of the poor ${ }^{6}$.

Given the above, this paper is related to those theoretical studies that emphasize the importance of accessing credit that can be, e.g., invested in human capital and how it can improve the mobility of the poor and reduce inequality. It is also related to those models that assume the existence of cash-in-advance constraints because of the possible (or impossible) substitution of cash (non-indexed) goods for credit (indexed) goods, particularly in times of high inflation. The relationship with the previous empirical studies is also significant, although we have to highlight that instead of further exploring the same route, we conduct a national and subnational analysis on the subject. Moreover, we use panel time series and time series data to conduct the analysis, instead of only one type of data variation. Furthermore, no less relevant is the importance of having access to financial markets as an insulation against poor macroeconomic performance, which is not, to our knowledge at least, explored elsewhere ${ }^{7}$.

\section{The Data}

\subsection{Description of the Data}

The data set comes from the Brazilian Institute of Geography and Statistics (IBGE), which is the Brazilian Census Bureau, the Brazilian Central Bank

\footnotetext{
${ }^{5}$ For good summaries on models with cash-in-advance constraints, see Blanchard and Fischer (1989) or Walsh (1998).

${ }^{6}$ It has to be said though, that the evidence presented by Bulir (1998), Dollar and Kraay (2002) and Clarke, Xu, et al. (2003) of the impact of financial development on inequality is not entirely satisfactory in terms of statistical significance.

${ }^{7}$ For more on the direct impact of macroeconomic performance (in the role of high inflation) on inequality in Brazil, see Cardoso, Barros, et al. (1995), Ferreira and Litchfield (1999), Barros, Corseuil, et al. (2000) and Bittencourt (2005).
} 
(BACEN) and the Institute of Applied Economic Research (IPEA) files. The IBGE is the most important institution for data collection and is the body that covers the Brazilian territory most thoroughly. The IPEA is an agency of the Brazilian government, that, among other things, compiles primary and provides secondary data coming from the IBGE and BACEN themselves.

The data on earnings come from the Monthly Employment Survey (PME) files compiled by the IBGE, which is a monthly rotative survey that covers six major regions over time and approximately 38,500 households drawn from a probabilistic sample. The six regions covered are, from north to south: Pernambuco, Bahia, Minas Gerais, Rio de Janeiro, São Paulo and Rio Grande do Sul. On aggregate these regions represent fifty nine percent of the total Brazilian population (as in 1996). The concept of before tax earnings adopted by the PME includes wages, monetary bonuses and fringe benefits earned by those at work, profits made by those who are self employed and employers, and the monetary value of goods for those earning in kind.

In a country which presented high inflation rates for such a long period of time the way the data is deflated is rather important. The earnings data are deflated by the IBGE's National Index of Consumer Prices (INPC). The INPC covers a basket of goods that families earning between one and eight times the monthly minimum wage, and whose head is employed and living in one of the regions, usually purchase ${ }^{8}$. One important prior adjustment is the use of a converter to express all data in Real $(\mathrm{R} \$)$ mainly because Brazil had many monetary reforms, especially between 1986 and 1994. Some adjustments in the INPC itself are also implemented. These include a correction of $22.25 \%$ for the inflation incurred in June 1994, a month before the full implementation of the $\mathrm{R} \$$. The reason is that the INPC calculated inflation using the price variations of a virtual, but not fully implemented $\mathrm{R} \$$, which was lower than the price variation incurred by the still existent and widely used Cruzeiro (CR\$). Another correction is the need to centre the INPC as if it was measuring inflation starting on the first day of each month, which is the date that most people get their paycheques. Taking into consideration that the information on earnings reported in the questionnaires of the PME is related to the first day of a particular reference month $t$, earnings are corrected by the deflator of month $t+1$ to allow the inflation incurred in $t$ to

${ }^{8}$ This information comes from the IBGE's Family Budget Survey and Products and Services Specification Survey. 
be accounted for ${ }^{9}$.

Given that, we use the information on individual earnings from people between fifteen and sixty five years of age to obtain the Gini coefficient, the Coefficient of Variation of the earnings distribution and the respective shares of the quintiles of the distribution by region and also for Brazil. These measures of inequality are used for having attractive properties. The Gini and the Coefficient of Variation are simultaneously consistent with the Anonymity, Population, Relative Income and Dalton principles, and are therefore Lorenz consistent. Furthermore, according to the Relative Income principle the shares are sufficient to measure inequality ${ }^{10}$.

The data used to construct the measures of financial development come from the BACEN and IBGE files. The national monetary aggregates, m2, $\mathrm{m} 3$, credit to the private sector (cps) and personal credit (cpsp) are originally from the BACEN's Monthly Bulletin. The first annualised monetary aggregate, $\mathrm{m} 2$, is defined as money in circulation, and current account and savings deposits. The second monetary aggregate, $\mathrm{m} 3$, is defined as $\mathrm{m} 2$ plus some other credit operations that do not present the same sort of high liquidity that the ones contained in $\mathrm{m} 2$ do. Credit to the private sector and personal credit are defined as credit provided by private and public institutions to the private sector (firms and individuals) and individuals only respectively ${ }^{11}$. These monetary aggregates are deflated by the IBGE's INPC.

The data on the regional Financial Domestic Product (fdp), and the regional and national General Domestic Products (gdp) are from the IBGE's National Accounts System. All these macroeconomic aggregates are calculated at market prices and deflated by the gdp implicit deflator.

We then calculate the ratios $\mathrm{m} 2 / \mathrm{gdp}, \mathrm{m} 3 / \mathrm{gdp}, \mathrm{cps} / \mathrm{gdp}$ and cpsp/gdp by region and for Brazil. To get these measures at national level we simply use the aforementioned national monetary aggregates over the national General Domestic Product. To construct the regional measures of financial development we have to take into account the fact that the information on monetary aggregates is national in scope. We then use the available national monetary

\footnotetext{
${ }^{9}$ See Corseuil and Foguel (2002) for more details on how to best deflate earnings and income data in Brazil.

${ }^{10}$ For more on inequality measures and their properties, see Sen (1997) or Ray (1999).

${ }^{11}$ It is important to include the participation of the public financial institutions in the mentioned monetary aggregates (cps and cpsp) because in Brazil they do provide the general public with the usual commercial financial services. Credit provided by public financial institutions that finance economic development is excluded, though.
} 
aggregates over the regional General Domestic Products multiplied by the percentage participation of each region in the total Financial Domestic Product to correct this discrepancy. The reason for doing so is that otherwise the most developed regions of the South would not appear as financially developed as they actually are. The weight used re-captures the importance of the most developed regions and provides a more accurate regional variation of financial development in Brazil. Definitions One and Two below illustrate the regional $\left(F D_{i t}\right)$ and national $\left(F D_{t}\right)$ measures of financial development respectively.

$$
F D_{i t}=\left(\text { mon.aggregates } t / g d p_{i t}\right) f d p_{i t},
$$

where $f d p_{i t}=f d p_{i} / f d p_{t}$ and

$$
F D_{t}=\text { mon.aggregates }{ }_{t} / g d p_{t} .
$$

Furthermore, the reason for using $\mathrm{m} 3 / \mathrm{gdp}$ in addition to the usual $\mathrm{m} 2 / \mathrm{gdp}$ is because of the financial repression problem existent in Brazil in the 1980's and first half of the 90 's. Although the inflation rates were notoriously high, the government kept the nominal interest rates on basic deposits and savings artificially low, and consequently generated negative real interest rates and a low $\mathrm{m} 2 / \mathrm{gdp}$ ratio $^{12}$. Moreover, the importance of the personal credit measure is because, unlike from the usual credit to the private sector measure, it captures the financial resources being allocated only to individuals, who might lack the initial wealth and collateral usually available to private firms.

Regarding the inflation rates, we use the variation on the IBGE's regional Consumer Price Indexes (IPCs) and the INPC. An advantage of these regional and national indexes is that they cover the Brazilian territory using information from very diverse regions. Although they do not cover the national territory completely, their coverage more than matches the regions surveyed by the PME, which is a convenient advantage for this paper ${ }^{13}$.

Table One presents the descriptive statistics of the national data and also the correlations between the measures of inequality and financial development during the period. It is worth mentioning the high means of the Gini and Coefficient of Variation (CV) of the earnings distribution and also that the poorest sixty percent (Q123) appropriated on average just $34 \%$ of the

\footnotetext{
${ }^{12}$ For more on the problem of financial repression in developing countries in general, see Agénor and Montiel (1999) or Easterly (2002).

${ }^{13}$ For more on these price indexes, see Corseuil and Foguel (2002).
} 
national earnings (the poorest forty percent (Q12) appropriated a mere $18 \%$ of the national earnings). With regards to the measures of financial development, it is important to mention at this point that the variable personal credit (cpsp/gdp) presents by far the smallest ratio of all. Inflation was on average at thirteen percent during the period, however it presents rates of virtually zero percent up to an astounding eighty two percent per month, which highlights its extreme volatility.

About the selected correlations on the second half of the Table, it is important to highlight the negative correlation between the Gini coefficient and all measures of financial development. Particularly eye-catching is the strong negative correlation between personal credit and the Gini. No less important is the positive correlation between the earnings share of the poorest forty percent of the population and the very same measures of financial development. Once more, personal credit presents a significant positive correlation with the shares of the poorest forty percent ${ }^{14}$.

Table 1: Descriptive Statistics and the Correlation Matrix, Brazil 1985-99

\begin{tabular}{lrrrrrr}
\hline \hline Variables & Obs & Mean & Std. Dev. & Min & Max \\
\hline Gini & 180 & 54.25 & 1.63 & 51 & & 58.20 \\
CV & 180 & 1.61 & .29 & 1.27 & 4.77 \\
Q12 & 180 & 18.51 & .93 & 15.78 & & 21.12 \\
Q123 & 180 & 34.18 & 1.18 & 30.42 & & 37.31 \\
m2/gdp & 180 & 133.77 & 50.42 & 53.60 & & 285.59 \\
m3/gdp & 180 & 199.37 & 69.73 & 79.16 & & 376.38 \\
cps/gdp & 180 & 193.12 & 35.06 & 113.26 & & 283.64 \\
cpsp/gdp & 180 & 15.61 & 9.55 & 3.17 & & 32.69 \\
Inflation & 180 & 13.76 & 15.16 & -.49 & & 82.18 \\
\hline Correlations & Gini & Q12 & m2/gdp & m3/gdp & cps/gdp & cpsp/gdp \\
\hline Gini & 1 & & & & & \\
Q12 & -.79 & 1 & & & & \\
m2/gdp & -.42 & .37 & 1 & & & \\
m3/gdp & -.37 & .32 & .97 & 1 & & \\
cps/gdp & -.29 & .19 & .61 & .69 & 1 & \\
cpsp/gdp & -.44 & .32 & .76 & .76 & .67 & \\
\hline \hline
\end{tabular}

Source: IBGE, BACEN, IPEA and author's own calculations.

\footnotetext{
${ }^{14}$ The correlations between the Coefficient of Variation and the shares of the poorest sixty percent to all measures of financial development present the same intuitive results as the ones reported in Table One. Available upon request.
} 


\subsection{Behaviour of the Data}

Earnings and income inequality in Brazil have historically been among the highest in the world. In Figure One we put the Gini coefficient and earnings share of the poorest forty percent of the distribution (Q12) together. We can see, e.g., how both inequality measures behaved during the hyperinflations of 1989-90 and in 1994, and after the stabilisation of 1995. The Gini saw a considerable increase, with the shares of the two lowest quintiles of the distribution shrinking during both hyperinflationary peaks and their immediate aftermaths. It is worth mentioning though, that after the implementation of the Real Plan in 1994, which has kept inflation reasonably under control since then, the Gini has been much more stable and somehow lower than in previous periods. Similarly, the shares of the two lowest quintiles of the distribution have shown a modest, but steady gain from 1995-96 onwards.

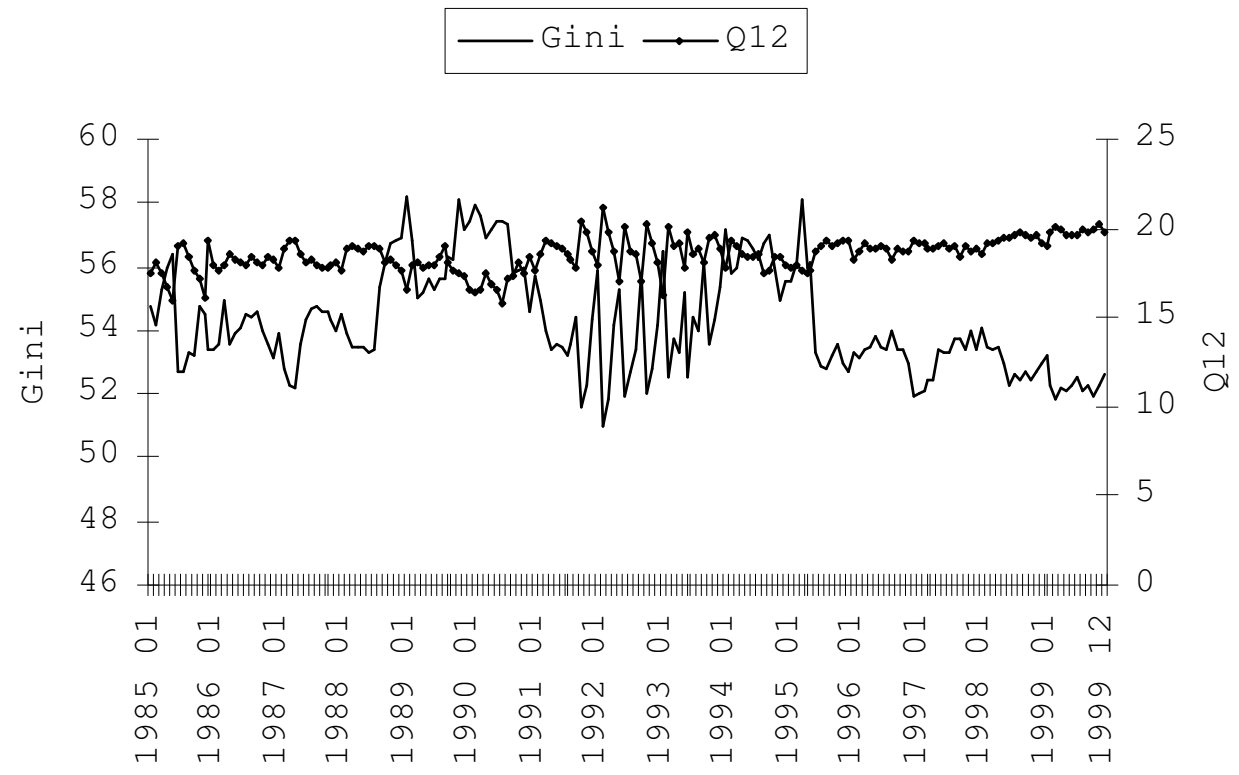

Figure 1: Earnings Inequality in Brazil. Source: PME, IBGE and author's own calculations.

With respect to the measures of financial development, in Figure Two we put together $\mathrm{m} 2 / \mathrm{gdp}$ and $\mathrm{m} 3 / \mathrm{gdp}$. Both measures presented sharp falls 
in 1989-90 and a more modest decrease again in 1994. However, after the stabilisation of 1995 they have consistently increased in importance. It is worth saying that both measures reached their pre 1989-90 levels only in 1997, which illustrates how badly the instability of the period affected financial development. Additionally, in Figure Three we graph credit to the private sector (cps/gdp) and personal credit (cpsp/gdp). Similarly to before, both measures reached rock bottom during and right after the hyperinflation of 1989-90, before consistently growing in size during the second half of the 1990's.

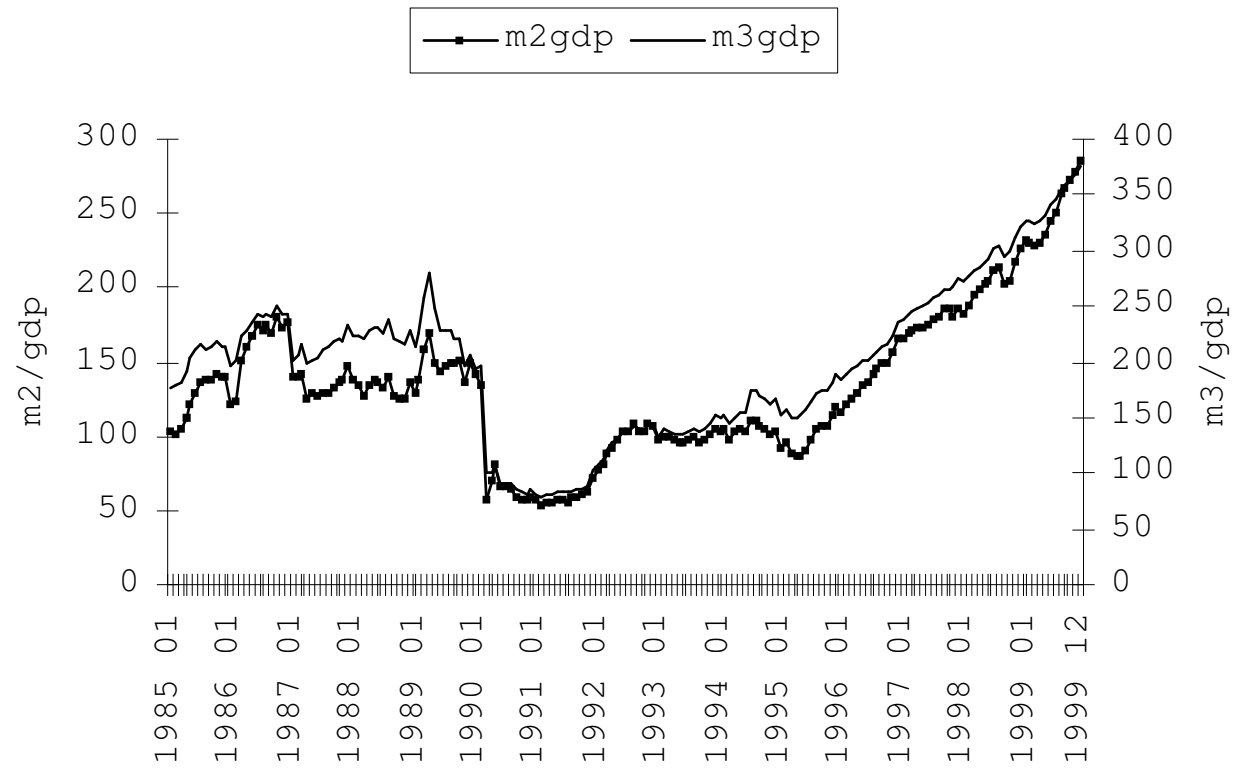

Figure 2: Financial Development in Brazil. Source: BACEN, IBGE, IPEA and author's own calculations. 


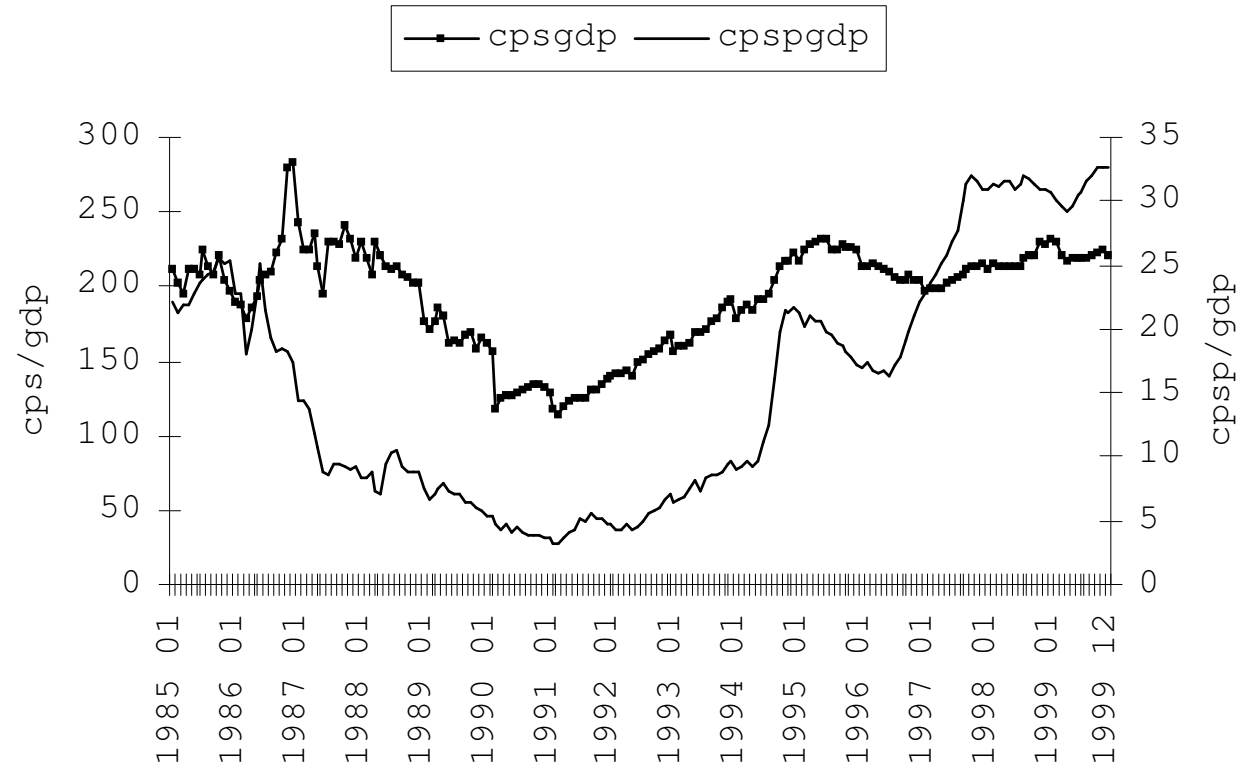

Figure 3: Financial Development in Brazil. Source: BACEN, IBGE, IPEA and author's own calculations.

Hence, what can be said about the above preliminary descriptive and visual evidence is that financial development and inequality moved in opposing directions in Brazil at the time. This highlights the importance of more access to financial and credit markets in reducing inequality and improving welfare and economic efficiency in such an unequal country. Also important to stress is that, particularly during the hyperinflation of 1989-90, there was a significant reduction in importance of all measures of financial development. This indicates that, because of the macroeconomic volatility and uncertainty existent at the time, only those well-endowed at the top of the earnings distribution managed to keep themselves in the financial and credit markets, and hence insulated against the poor macroeconomic performance and with enough credit to be invested in productive activities. Coincidently, inequality increased considerably during the same period. Moreover, the importance of having a stable macroeconomic environment that actually encourages the growth of financial and credit markets and consequently reduces inequality. All measures of financial development significantly increased in size from 
1995-96 onwards and inequality modestly, but steadily, decreased during the same period of macroeconomic stability.

\section{Empirical Strategy and Results}

\subsection{Strategy}

We understand that the regional financial development measures in our panel time series $T \succ N$ data, as originally set, present a measurement discrepancy that although corrected and minimised by the factor $f d p_{i t}$ can cause a statistical endogeneity $E\left(x_{i t} u_{i t}\right) \neq 0$ problem. Additionally to that, some would argue that there is a possible economic endogeneity problem, i.e., reverse causality between inequality and financial development. Furthermore, although the time series $T \rightarrow \infty$ data do not present us with a measurement issue, we do consider the possibility of a prospective reverse causality problem there too.

When using the panel time series data, we firstly estimate benchmark equations using the Pooled Ordinary Least Squares estimator (POLS) and secondly, equations in First Differences with Instrumental Variables (FDIV). The reason for using the FDIV estimator is because it deals with the possible statistical endogeneity caused by the discrepancy in our regional financial development measures and also with the possibility of reverse economic causality. This sort of estimator is based on the assumption of sequential exogeneity $E\left(x_{i t-2} u_{i t}\right)=0$ or $E\left(\Delta x_{i t-1} \Delta u_{i t}\right)=0$, i.e., the first two lags or the lagged first difference of the endogenous explanatory variable are valid identifying instruments by default. Hence, we use the first two lags of the measure of financial development being estimated as our identifying instruments $^{15}$. The estimates provided by this FDIV estimator are asymptotically consistent and efficient ${ }^{16}$. Equations Three and Four illustrate the POLS and FDIV estimators, respectively.

$$
I_{i t}=\alpha+\beta F D_{i t}+\gamma I N F L_{i t}+u_{i t},
$$

\footnotetext{
${ }^{15}$ The lagged first differences and the first two lags of the endogenous explanatory variable are linearly equivalent. See Wooldridge (2002).

${ }^{16}$ Additionally, it is worth remembering that a spurious regression under $T \succ N$ is less of a problem. This is because the pooled estimators are averaging over the regions, and therefore the noise is attenuated and the estimates consistent. See Phillips and Moon (1999).
} 


$$
\Delta I_{i t}=\beta \Delta F D_{i t}+\gamma \Delta I N F L_{i t}+\Delta u_{i t},
$$

where $\alpha$ is the homogeneous intercept of the benchmark POLS estimator, $I_{i t}$ is either the Gini, or the Coefficient of Variation, or the quintile shares of the earnings distribution, $F D_{i t}$ is the particular measure of financial development being estimated, $I N F L_{i t}$ the inflation rates and $u_{i t}$ the residuals.

For the time series data we estimate a benchmark Ordinary Least Squares (OLS) and then use the Instrumental Variable (IV) estimator with robust standard errors to account for the possible reverse causality problem. The identifying instruments used are the first two lags of the particular financial development measure being estimated. Equation Five illustrates it.

$$
I_{t}=\alpha_{t}+\beta F D_{t}+\gamma I N F L_{t}+\delta O V_{t}+u_{t},
$$

where $I_{t}$ is the Gini coefficient of the earnings distribution, $F D_{t}$ is the financial development measure being estimated, $I N F L_{t}$ the inflation rates, $O V_{t}$ the other cyclical variables included (gdp and squared gdp per capita) and $u_{t}$ the residuals.

Furthermore, the regression-based Hausman tests are used to test for endogeneity in all specifications $(T \succ N$ and $T \rightarrow \infty)$ and for overidentifying restrictions in the time-series specifications.

Moreover, as mentioned in Section Two, because the data available cover two very distinct periods of the recent Brazilian economic history, when estimating the panel time series we split the sample to better examine the impact of not only financial development, but also inflation on inequality during these periods. The initial intuition suggests that during the low-inflation period (1995-99) not only inflation would be progressive on inequality through the debtor and creditor channel (as in developed countries), but also financial development would present bigger progressive effects on inequality than during the high-inflation period (1985-94). This is because during the period of stable macroeconomic performance access to financial and credit markets would expand, therefore benefiting the poor. Finally, the time series is used to estimate equations using the whole sample (1985-99), and with extra cyclical variables mainly as a robustness check for the panel time series estimates. 


\subsection{Results}

We report in Table Two the main results obtained by using the panel time series data covering first the volatile period of 1985-94. When we estimate benchmark equations using the POLS estimator and the Coefficient of Variation of the earnings distribution as the measure of inequality, all financial development measures present progressive effects on inequality and all estimates are statistically significant. The other explanatory variable estimated, inflation rates, present regressive effects on inequality, as expected during this period. The Hausman regression-based test for endogeneity suggests that we can actually not reject the null of no endogeneity, which indicates that the measurement discrepancy mentioned before is less of a problem here. The $F$ test for overall significance of the regressors rejects the null and the $R^{2}$ is of a reasonable size.

When we take into consideration the measurement discrepancy (which, according to the Hausman test turns out not to be an issue after all) and the reverse causality issues, the FDIV estimator delivers a similar story. All financial development measures present significant progressive effects on the Coefficient of Variation and inflation confirms its regressiveness during this period of poor macroeconomic performance ${ }^{17}$. It is worth saying that the progressive effect of the financial development measures more than compensates for the regressive effects of inflation on inequality in most equations estimated for the period. Moreover, the measure personal credit (cpsp/gdp) is the variable presenting the largest estimates of all, indicating the importance of access to credit by people who might lack collateral and initial wealth in reducing inequality ${ }^{18}$.

\footnotetext{
${ }^{17}$ Alternatively, in specifications with the Gini coefficient as the measure of inequality, all estimates confirm the ones reported in Table Two in terms of economic and statistical significance. Available upon request.

${ }^{18}$ In specifications having past financial development and past inflation as explanatory variables, all estimates confirm the ones reported in Table Two in terms of economic and statistical significance. Available upon request.
} 
Table 2: Estimates of Financial Development on Inequality, Regions 1985-94

\begin{tabular}{|c|c|c|c|c|}
\hline & \multicolumn{4}{|c|}{ POLS (Coefficient of Variation) } \\
\hline $\mathrm{m} 2 / \mathrm{gdp}$ & $-.080(-7.07)$ & & & \\
\hline $\mathrm{m} 3 / \mathrm{gdp}$ & & $-.049(-6.80)$ & & \\
\hline cps/gdp & & & $-.056(-7.00)$ & \\
\hline cpsp/gdp & & & & $-.596(-5.78)$ \\
\hline Inflation & $.0080(11.61)$ & $.0080(11.54)$ & $.0079(11.39)$ & $.0067(8.68)$ \\
\hline Constant & $1.55(70.79)$ & $1.54(71.14)$ & $1.56(67.65)$ & $1.54(65.19)$ \\
\hline Hausman test & -.73 & -.74 & .87 & -.18 \\
\hline F test & 109.70 & 107.31 & 109.06 & 99.36 \\
\hline \multirow[t]{2}{*}{$\mathrm{R}^{2}$} & .25 & .25 & .25 & .23 \\
\hline & \multicolumn{4}{|c|}{ FDIV ( $\Delta$ Coefficient of Variation) } \\
\hline$\Delta \mathrm{m} 2 / \mathrm{gdp}$ & $-.065(-2.50)$ & & & \\
\hline$\Delta \mathrm{m} 3 / \operatorname{gdp}$ & & $-.059(-3.73)$ & & \\
\hline$\Delta \mathrm{cps} / \mathrm{gdp}$ & & & $-.030(-2.14)$ & \\
\hline$\Delta \mathrm{cpsp} / \mathrm{gdp}$ & & & & $-1.158(-9.06)$ \\
\hline$\Delta$ Inflation & $.030(32.32)$ & $.030(31.27)$ & $.031(33.87)$ & $.025(24.12)$ \\
\hline Obs & 636 & 636 & 636 & 636 \\
\hline
\end{tabular}

T-ratios in parentheses. Source: author's own calculations.

Table Three reports the main results covering the period of relative stable macroeconomic performance (1995-99) also using the panel time series variation in the data. The first half of the Table presents the benchmark POLS estimates of financial development on the earnings of the poor, i.e., the shares of the forty percent poorest in the earnings distribution (Q12). All measures of financial development help to increase the poor's share in the distribution. Inflation, differently from expected in times of low inflation rates, presents a regressive effect on the earnings of the poor. The Hausman test again suggests that we can accept the null of no endogeneity. The $F$ test rejects the null and the $R^{2}$ is reasonable.

When we use the FDIV estimator in the second half of the Table the story is repeated. Financial development has the ability again of increasing the poor's share, with inflation being regressive once more. This regressiveness of inflation is because, although Brazil presented a much more stable macroeconomic environment in the second half of the 1990's, the inflation rates for the period were, on average, still at nine percent, which proved regressively 
enough for those at the bottom of the distribution ${ }^{19}$. Personal credit proved to be the measure with the largest estimates once again, highlighting the importance of more widespread access to credit markets in improving the welfare of the poor $^{20}$.

Table 3: Estimates of Financial Development on Inequality, Regions 1995-99

\begin{tabular}{|c|c|c|c|c|}
\hline & \multicolumn{4}{|c|}{ POLS (Q12) } \\
\hline $\mathrm{m} 2 / \mathrm{gdp}$ & $.368(6.56)$ & & & \\
\hline $\mathrm{m} 3 / \mathrm{gdp}$ & & $.255(6.45)$ & & \\
\hline cps/gdp & & & $.298(5.61)$ & \\
\hline cpsp/gdp & & & & $2.277(5.81)$ \\
\hline Inflation & $-.200(-2.12)$ & $-.238(-2.56)$ & $-.476(-5.18)$ & $-.236(-2.48)$ \\
\hline Constant & $18.63(144.66)$ & $18.64(145.32)$ & $18.80(157.05)$ & $18.70(143.57)$ \\
\hline Hausman test & -.87 & .67 & -.45 & .06 \\
\hline F test & 31.65 & 30.88 & 25.49 & 26.69 \\
\hline \multirow[t]{2}{*}{$\mathrm{R}^{2}$} & .18 & .17 & .15 & .15 \\
\hline & \multicolumn{4}{|c|}{ FDIV $(\Delta \mathrm{Q} 12)$} \\
\hline$\Delta \mathrm{m} 2 / \mathrm{gdp}$ & $.244(3.66)$ & & & \\
\hline$\Delta \mathrm{m} 3 / \mathrm{gdp}$ & & $.187(3.94)$ & & \\
\hline$\Delta \mathrm{cps} / \mathrm{gdp}$ & & & $.324(5.23)$ & \\
\hline$\Delta \operatorname{cpsp} / \operatorname{gdp}$ & & & & $2.270(4.31)$ \\
\hline$\Delta$ Inflation & $-1.090(-10.65)$ & $-1.126(-12.40)$ & $-1.430(-23.66)$ & $-1.192(-15.69)$ \\
\hline Obs & 280 & 280 & 280 & 280 \\
\hline
\end{tabular}

T-ratios in parentheses. Source: author's own calculations.

When we explore the time series variation in the data and the whole sample (1985-99) with information for Brazil the results confirm the ones reported above. The benchmark OLS estimates with the Gini coefficient as the measure of inequality are mostly significant and all economically meaningful. Inflation is, as already expected by now, regressive on inequality. The Hausman test suggests that all measures of financial development are exogenous.

\footnotetext{
${ }^{19}$ When we use the Gini coefficient as the measure of inequality, all measures of financial development present progressive effects and inflation kept its regressive impact on inequality. Results available upon request.

${ }^{20}$ In specifications with past financial development and past inflation as explanatory variables, all estimates confirm the ones reported in Table Three in terms of economic and statistical significance. Available upon request.
} 
The IV regressions confirm the above results with most estimates being statistically and economically significant ${ }^{21}$. The IV estimator with extra cyclical variables (reported at the bottom of the table) confirm all previous results too. Financial development and inflation have the right signs and are statistically significant. Personal credit is the measure of financial development presenting the largest estimates once again. Additionally, we use the gdp and squared gdp per capita to test for the classical Kuznets hypothesis. The Kuznets hypothesis holds in terms of having the right signs (initially inequality increases and only on a second stage of economic development inequality comes down) and being statistically significant. However, the size of the squared gdp estimates are very small, and therefore not entirely economically significant. When we run the Hausman regression-based $N R^{2}$ test for overidentifying restrictions, it suggests that in all equations the instruments are valid. The $F$ test rejects the null and the $R^{2}$ is of a reasonable size. Table Four reports the results.

\footnotetext{
${ }^{21}$ As before, in specifications with the Coefficient of Variation of the earnings distribution as the measure of inequality, all estimates confirm the ones reported in Table Four in terms of economic and statistical significance. Available upon request.
} 
Table 4: Estimates of Financial Development on Inequality, Brazil 1985-99

\begin{tabular}{|c|c|c|c|c|}
\hline & \multicolumn{4}{|c|}{ OLS (Gini) } \\
\hline $\mathrm{m} 2 / \mathrm{gdp}$ & $-.0085(-3.80)$ & & & \\
\hline $\mathrm{m} 3 / \mathrm{gdp}$ & & $-.0047(-2.90)$ & & \\
\hline cps/gdp & & & $-.0029(-.84)$ & \\
\hline cpsp/gdp & & & & $-.0351(-2.39)$ \\
\hline Inflation & $.0419(5.63)$ & $.0443(5.82)$ & $.0503(6.26)$ & $.0390(4.21)$ \\
\hline Constant & $54.81(148.38)$ & $54.59(136.44)$ & $54.12(73.02)$ & $54.26(157.29)$ \\
\hline Hausman test & -.64 & -1.18 & .72 & .27 \\
\hline F test & 38.63 & 34.64 & 29.53 & 32.84 \\
\hline \multirow[t]{2}{*}{$\mathrm{R}^{2}$} & .30 & .28 & .25 & .27 \\
\hline & \multicolumn{4}{|c|}{ IV (Gini) } \\
\hline $\mathrm{m} 2 / \mathrm{gdp}$ & $-.0082(-3.76)$ & & & \\
\hline $\mathrm{m} 3 / \mathrm{gdp}$ & & $-.0044(-2.54)$ & & \\
\hline $\operatorname{cps} / g d p$ & & & $-.0037(-.91)$ & \\
\hline cpsp/gdp & & & & $-.0363(-2.65)$ \\
\hline Inflation & $.0423(5.91)$ & $.0450(6.36)$ & $.0495(7.23)$ & $.0386(4.84)$ \\
\hline Constant & $54.76(131.46)$ & $54.51(116.19)$ & $54.28(60.55)$ & $54.27(154.00)$ \\
\hline $\mathrm{NR}^{2}$ & .52 & 1.39 & .48 & 1.10 \\
\hline $\mathrm{F}$ test & 54.28 & 47.43 & 44.52 & 43.76 \\
\hline $\mathrm{R}^{2}$ & .30 & .28 & .25 & .27 \\
\hline $\mathrm{m} 2 / \operatorname{gdp}$ & $-.0109(-4.88)$ & & & \\
\hline $\mathrm{m} 3 / \operatorname{gdp}$ & & $-.0074(-4.01)$ & & \\
\hline cps/gdp & & & $-.0156(-3.50)$ & \\
\hline cpsp/gdp & & & & $-.0275(-1.88)$ \\
\hline Inflation & $.0399(5.36)$ & $.0394(5.31)$ & $.0310(3.94)$ & $.0349(4.30)$ \\
\hline gdp & $.0853(5.24)$ & $.0950(5.78)$ & $.1246(6.65)$ & $.0891(4.94)$ \\
\hline $\operatorname{gdp}^{2}$ & $-.000005(-5.20)$ & $-.000005(-5.76)$ & $-.000007(-6.66)$ & $-.000005(-4.94)$ \\
\hline Constant & $-295.94(-4.44)$ & $-333.34(-4.98)$ & $-453.21(-5.93)$ & $-309.38(-4.21)$ \\
\hline $\mathrm{NR}^{2}$ & .00 & .28 & 2.51 & 3.60 \\
\hline F test & 53.06 & 47.77 & 42.50 & 38.03 \\
\hline $\mathrm{R}^{2}$ & .41 & .40 & .39 & .36 \\
\hline
\end{tabular}

T-ratios in parentheses. Source: author's own calculations.

Given the evidence above, we can confidently say that financial development is proved important under more stable or even unstable macroeconomic conditions through the investment in productive activities channel. The es- 
timates of personal credit are the largest ones in all equations presented and the estimates of credit to the private sector fare very well too, which highlights the potential of these particular measures in reducing inequality and improving welfare and economic efficiency in Brazil ${ }^{22}$. Furthermore, the estimates of those measures more related to access to indexed financial assets, i.e., $\mathrm{m} 2 / \mathrm{gdp}$ and $\mathrm{m} 3 / \mathrm{gdp}$, present the right signs, indicating the importance of some sort of indexed earnings protection against the high inflation existent in periods of poor macroeconomic performance.

All in all, the results are statistically and economically significant, and robust for a wide range of inequality and financial development measures, estimators and specifications, and time periods, which reinforces the importance of these findings.

\section{Concluding Remarks}

In this paper we examined the importance of financial development, i.e., more broad access to financial and credit markets in alleviating earnings inequality, and therefore improving the welfare of the poor in Brazil during the 1980's and 90's.

The wide range of results presented in Sections Two and Three confirm the theoretical prediction that more access to credit markets, particularly by the poor, has a positive impact in reducing inequality through the investment in productive activities channel. Moreover, financial development proved to be important also via the access to indexed goods channel, i.e., access to financial markets actually provided insulation against the poor macroeconomic performance recurrently existent in Brazil during the 1980's and first half of the 90's.

The significance of these results is mainly because: firstly, we undertake a national and subnational analysis, which pinpoints more accurately the impact of financial development on inequality in a major developing and very unequal country like Brazil. Secondly, in addition to the usual measures of financial development we propose alternative measures that we believe capture more realistically the Brazilian economic reality at the time. Furthermore, the results are statistically and economically significant and robust

\footnotetext{
${ }^{22}$ Incidently, Khandker (2003) advocates that the microfinance experiment in Bangladesh helped to reduce extreme poverty and Burgess and Pande (2004) suggest that the Indian rural branch expansion program helped to reduce rural poverty.
} 
for different data sets (panel time series and time series), different measures of inequality (Gini, Coefficient of Variation and quintile shares) and financial development (m2/gdp, m3/gdp, credit to the private sector and personal credit), different specifications and estimators (OLS, POLS, IV and FDIV) and different time periods (1985-94, 1995-99 and 1985-99).

The main limitation at this point concerns the data available, though. The information on monetary aggregates used to construct the measures of financial development is still only provided at national level. Although we explore the regional variation of the data, correcting and minimising the possible discrepancy present, we understand that the provision of regional information on the monetary aggregates would certainly bring more flexibility than we have at the moment in terms of empirical modelling. At the same time, this temporal limitation can not act as an impediment to carry out such studies. We do manage to minimise the discrepancy caused by the lack of regional information on monetary aggregates and construct exogenous regional measures of financial development that deliver significant and robust results. Moreover, at the moment there is no data on financial assets at an individual level in Brazil, which would disaggregate this sort of information even further. Certainly the availability of these sorts of data would allow us to investigate not only access to credit by the poor, but also how well or badly they are actually repaying their debts.

The main implication arising from the evidence is that the policy of making financial and credit markets more widely available has the advantage of being a non-distortionary fiscal policy that clearly reduces the persistent inequality present in Brazil, and that therefore improves the welfare of the poor without affecting economic efficiency ${ }^{23}$. To corroborate with that, the personal credit measure, although the smallest in size, presented the largest estimates in all equations. This highlights the importance of credit being allocated on a more individual level and how efficiently it helps to reduce inequality or to increase the earnings share of the poor. A natural extension of this paper would be an investigation of the impact (negative presumably) of inflation on financial development itself, i.e., how the poor macroeconomic performance of the 1980's and first half of the 90's directly affected the provision of credit and access to financial markets to those at the bottom and middle of the distribution, and with that indirectly affecting inequality.

\footnotetext{
${ }^{23}$ Redistributive fiscal policies are usually criticised on grounds of creating certain inefficiencies, e.g., higher unemployment that affects mostly the poor and their earnings.
} 


\section{References}

[1] Agénor, P.-R. and P. Montiel (1999). Development Macroeconomics. Princeton, New Jersey, Princeton University Press.

[2] Aghion, P. and P. Bolton (1992). "Distribution and Growth in Models of Imperfect Capital Markets." European Economic Review 36: 603-611.

[3] Aghion, P. and P. Bolton (1997). "A Theory of Trickle-Down Growth and Development." Review of Economic Studies 64: 151-172.

[4] Aghion, P., E. Caroli, et al. (1999). "Inequality and Economic Growth: The Perspective of the New Growth Theories". Journal of Economic Literature 37(Dec).

[5] Banerjee, A. and A. Newman (1993). "Occupational Choice and the Process of Development." Journal of Political Economy 101(21).

[6] Barros, R. P. d., C. Corseuil, et al. (2000). "Poverty, Inequality and Macroeconomic Instability". Brazilian Journal of Applied Economics 4(4): 743-761.

[7] Beck, T., A. Demirguc-Kunt, et al. (2004). Finance, Inequality, and Poverty: Cross-Country Evidence. NBER Working Paper Series.

[8] Besley, T. and R. Burgess (2003). "Halving Global Poverty." Journal of Economic Perspectives 17(3): 3-22.

[9] Bittencourt, M. (2005). Macroeconomic Performance and Inequality: Brazil 1983-94. Centre for Market and Public Organisation Working Paper.

[10] Blanchard, O. and S. Fischer (1989). Lectures on Macroeconomics. Cambridge, Massachusetts, The MIT Press.

[11] Bulir, A. (1998). Income Inequality: Does Inflation Matter? IMF Working Paper.

[12] Burgess, R. and R. Pande (2004). Do Rural Banks Matter? Evidence from the Indian Social Bank Experiment. LSE. 
[13] Cardoso, E., R. P. d. Barros, et al. (1995). Inflation and Unemployment as Determinants of Inequality in Brazil: The 1980's. Reform, Recovery, and Growth. R. Dornbusch and S. Edwards. Chicago and London, The University of Chicago Press.

[14] Clarke, G., L. Xu, et al. (2003). Finance and Income Inequality: Test of Alternative Theories. World Bank Policy Research Working Paper.

[15] Cooley, T. F. and G. D. Hansen (1989). "The Inflation Tax in a Real Business Cycle Model." American Economic Review 79(4): 733-748.

[16] Corseuil, C. and M. Foguel (2002). Uma Sugestão de Deflatores para Rendas Obtidas a Partir de Algumas Pesquisas Domiciliares do IBGE. IPEA Texto para Discussão.

[17] Dollar, D. and A. Kraay (2002). "Growth is Good for the Poor." Journal of Economic Growth 7: 195-225.

[18] Easterly, W. (2002). The Elusive Quest for Growth. Cambridge, Massachusetts, The MIT Press.

[19] Ferreira, F. and J. Litchfield (1999). Education or Inflation? LSE Discussion Paper.

[20] Galor, O. and J. Zeira (1993). "Income Distribution and Macroeconomics." Review of Economic Studies 60: 35-52.

[21] Greenwood, J. and B. Jovanovic (1990). "Financial Development, Growth, and the Distribution of Income." Journal of Political Economy $98(5)$.

[22] Honohan, P. (2004). Financial Development, Growth and Poverty: How Close are the Links? World Bank Policy Research Working Paper.

[23] Khandker, S. (2003). Micro-finance and Poverty: Evidence Using Panel Data from Bangladesh. World Bank Policy Research Working Paper.

[24] Kuznets, S. (1955). "Economic Growth and Income Inequality." The American Economic Review 45(1). 
[25] Inter-American Development Bank (2005). Unlocking Credit: The Quest for Deep and Stable Lending. IDB Report on Economic and Social Progress in Latin America.

[26] Li, H., L. Squire, et al. (1998). "Explaining International and Intertemporal Variations in Income Inequality." The Economic Journal 108: 2643.

[27] Loury, G. (1981). "Intergenerational Transfers and the Distribution of Earnings." Econometrica 49(4).

[28] Lucas, R. E. and N. Stokey (1987). "Money and Interest in a Cash-inAdvance Economy." Econometrica 55(3): 491-514.

[29] Piketty, T. (1997). "The Dynamics of the Wealth Distribution and the Interest Rate with Credit Rationing." Review of Economic Studies 64: 173-189.

[30] Phillips, P. and H. R. Moon (1999). "Linear Regression Limit Theory for Nonstationary Panel Data." Econometrica 67(5): 1057-1112.

[31] Ray, D. (1999). Development Economics. Princeton, Princeton University Press.

[32] Sen, A. (1997). On Economic Inequality. Oxford, Oxford University Press.

[33] Smith, R. and A.-M. Fuertes (2004). Panel Time Series. cemmap, IFS.

[34] Walsh, C. (1998). Monetary Theory and Policy. Cambridge, Massachusetts, The MIT Press.

[35] Windmeijer, F. (2003). Panel/Longitudinal Data Analysis Course. cemmap, IFS.

[36] Wooldridge, J. (2002). Econometric Analysis of Cross Section and Panel Data. Cambridge, Massachusetts, The MIT Press. 